\author{
Н.В. Богданова-Бегларян \\ Санкт-Петербургский государственный университет \\ (Россия, Санкт-Петербург) \\ n.bogdanova@spbu.ru
}

\title{
ФОНЕТИЧЕСКИЙ ТЯНИ-ТОЛКАЙ: О ДВУХ РАЗНОНАПРАВЛЕННЫХ ТЕНДЕНЦИЯХ В ПОСТРОЕНИИ УСТНОГО ТЕКСТА
}

Статья посвящена описанию двух разнонаправленных тенденций в построении устного дискурса. На лексическом и синтаксическом уровнях в русском языке особенно активно и плодотворно действует закон экономии, порождая в результате сжатия, редукции, компрессии звуковой формы одних единиц - другие, новые, находящиеся на разных этапах своего пути к признанию системой языка (деструкция ведет к созиданию). Наиболее ярким примером такого созидания в результате компрессии являются лексикализованные редуцированные формы многих, в первую очередь сверхчастотных, русских слов: тыщиа, щуас, пийсят, здрасьте, сёдня, чек (человек), грит и т. П. Проявлением закона экономии можно считать также употребление в речи аппроксиматоров разного типа, заменяющих ряд перечисления или его часть, передаваемую говорящим чужую (или свою собственную, сказанную ранее) речь или опять же ее часть: и всё такое (прочее), пятое-десятое, то-сё, бла-бла-бла. На текстовом же, дискурсивном уровне нашей устной речи обнаруживаются явления диаметрально противоположного толка, а именно - абсолютно неэкономное расширение, приращение формы без всякого приращения смысла. Осуществляется это приращение за счет большого количество немотивированных (хезитационных) пауз, неречевых хезитативов (э-э, $a-a, m-м$ ), а также за счет использования различных прагматем, помогающих говорящему порождать и структурировать свою речь: это вербальные хезитативы (это самое, как его, я не знаю, ну в общем), паралингвистические явления (смех, вздох, кашель, причмокивание, цоканье языком и пр.) и т. п. Эти две разнонаправленные тенденции - сокращение и приращение - обеспечивают устной речи ту специфику (своеобразный речевой Тяни-Толкай), которая требует постоянного исследовательского внимания.

Ключевые слова: спонтанная речь, закон экономии, редуцированная форма, речевая компрессия, хезитация, вербальный хезитатив, прагматема

Что может быть банальнее утверждения, что главной движущей силой эволюции языка является принциип экономии? Ср.: в работе языка как живого организма заметно «стремление к экономии сил и нерастрачиванию их без нужды» [Бодуэн 
де Куртенэ 1963: 226]; в процессе развития, следуя «естественным законам эволюции», язык движется от более сложных к более простым способам выражения того же содержания [Спенсер 1986: 172]; «для языковой деятельности характерна тенденция к бережливости», «в языке для всех случаев вырабатываются способы выражения, которые содержат ровно столько, сколько необходимо для понимания» [Пауль 1960: 302]; язык постоянно стремится освободиться от лишнего [Passy 1990: 229]; и т.д., и т. п. Наиболее наглядно это видно именно на «оси речи» [Frei 1929], т. е. прежде всего на фонетическом уровне.

О принципе экономии писали многие, отмечая, в частности, его двойственный характер: лингвистическая экономия, являясь, по сути, деструктивной, оказывается в то же время и созидательной. Именно так, можно предположить, возникли в языке такие явления, как неполные и нечленимые предложения, аббревиатуры и сложносокращенные слова, многие лексические единицы (Публичка, Ленинка, нетленка), в том числе маркеры-аппроксиматоры, заменяющие ряд перечисления (и так далее, и всё такое (прочее), пятое-десятое) или чужую (или свою собственную, сказанную ранее) речь (бла-бла-бла, ля-ля-тополя).

На лексическом и синтаксическом уровнях закон экономии в русском языке действует особенно активно и плодотворно, порождая в результате сжатия, редукции, компрессии звуковой формы одних единиц - другие, новые, находящиеся на разных этапах своего пути к признанию системой языка (деструкция $\rightarrow$ созидание).

На фонетическом уровне наиболее ярким примером такого созидания являются практически лексикализованные редуцированные формы (РФ) типа здрасьте, щзас, тыщща и т. п. Анализ корпусного материала [www.ruscorpora.ru] показал, что письменная фиксация таких форм началась более 200 лет назад:

- 1790 г. - неча (П. А. Плавильщиков, выдающийся актер и писатель),

- 1810 г. - мня (А.Е. Лабзина, русская мемуаристка),

- И отчего у те болезь? [Ф. М. Решетников. Тетушка Опарина (1868)].

Свидетельствами на наших глазах происходящей лексикализации редуцированных форм многих (в первую очередь - сверхчастотных) русских слов можно считать целый ряд признаков (см. об этом подробнее: [Стойка 2017]):

- наличие и вариативность орфографического представления: щุa, щуас, счас, сичас, сечас; ваще и воще;

- морфологизация: ваше величество $\rightarrow$ вашество $\rightarrow$ ваше вашество;

- «фонетизация»: жизнь $\rightarrow$ жизь $\rightarrow$ жись $\rightarrow$ жысь; собсно $\rightarrow$ собсна $\rightarrow$ сопсна;

- «орфографизация»: здрасть вм. здраст, слушь - как отрежь, усльишь, сёд-

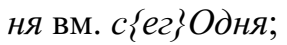

- ресемантизация $\rightarrow$ дифференциация значений полной и редуцированной форм слова (жизнь $\neq$ жысь), ср.:

1) Сам Жора написал где-то к тридияати годам десять рассказов. И с тех пор переиздал их десять тысяч раз, по-разному компонуя и подчас переименовывая (так, «Жизнь» превратилась в «Жысь») [В. Топоров: Большая жратва Жоры Жирняго (2008)]. 
По данным электронного опроса, проведенного в среде носителей русского языка [Стойка 2017], эти две формы - жизнь и жысь - действительно несколько разошлись по значению: по мнению большинства респондентов, жжысь - это трудная, горькая, обыденная жсизнь.

В ходе анализа корпусного материала обнаружилась и любопытная зависимость употребления полной или редуцированной формы слова от интенции говорящего, ср.:

2) [Мужчина2, муж] Восемьсот тым за каждого [Юля, жен] Восемьсот? [Оля, жен] Тысяч? [Юля, жен] За каждого? [Мужчина2, муж] Да / за каждого [Разговоры за игрой в карты (2009)];

3) [Олег, С. Астахов, муж, 34, 1969] Где триста тысяч? [Кирыч, муж] Какие... какие триста тыщ / товарищ? [В. Бутурлин, В. Еремин. Есть идея, к/ф (2003)].

В контекстах (2)-(3) хорошо видно, что говорящий, для которого упоминаемая в диалоге сумма не представляется слишком большой, употребляет РФ тыщща, тогда как его собеседник, с иным отношением к этой сумме, предпочитает полную формы тысяяа. Такой пример в материале исследования оказался отнюдь не единственным.

- десемантизация $\rightarrow$ прагматикализация $\rightarrow$ новые слова. В частности, результатом такого процесса могут стать междометные прагматемы разного типа:

4) - Я те щцас поговорю, «сбесился», - сказал хозяин [Г. Владимов. Верный Руслан (1963-1965)];

5) - Щас как пихнусь - костей не соберешь. [В. Рыбаков. Трудно стать Богом (1996)];

6) [Марина, жен] Я? Ха! Щас прям! Недостойны они этого! [Разговор двух подруг (2006)];

7) - В ЗАГС? Щас! - любил он повторять [Е. Тихонова. Жениться надо на училках! (2004) // Амурский Меридиан (Хабаровск). 2004. 12.22];

8) - Вы не хотите ин... оформить инвалидность? \# Так а(:) / кто / а кто мне её (...) да... даст ? \# Здрасьте! Тут по... по вашим болячкам / я тут почитала / у вас куча болячек (ОРД);

\footnotetext{
${ }^{1}$ Основной массив иллюстраций в настоящей статье - из двух корпусов русского языка: Национального (НКРЯ) и Звукового (ЗКРЯ); последний включает два разных модуля: подкорпус повседневной русской речи «Один речевой день» (ОРД; преимущественно диалоги и полилоги) и собрание монологов «Сбалансированная аннотированная текстотека» (САТ). Подробнее о ЗКРЯ см.: [Богданова-Бегларян (отв. ред.) 2013; Богданова-Бегларян и др. 2015; Богданова-Бегларян и др. 2017а; Богданова-Бегларян и др. 2017б; Bogdanova-Beglarian et al. 2016; БогдановаБегларян (отв. ред.) 2016]. Об особенностях орфографического представления расшифровок (транскриптов) ОРД см.: [Богданова-Бегларян (отв. ред.) 2016: 242-243].
} 
9) а тыл же старие Сашки\% / да? *Пна один год // *П\# ну здраст / на десять лет ! (ОРД);

10) так / заставка // вот заставка // а что ж это у меня получилось-то ? *П чистый лист / драсьте пожалста! (ОРД).

- десемантизация $\rightarrow$ прагматикализация $\rightarrow$ новые единицы. Результат этого процесса трудно назвать словом в общепринятом смысле этого термина. Однако данный процесс, вне всякого сомнения, приводит к появлению в речи неких новых единиц, отличающихся высокой употребительностью и воспроизводимостью в речи разных говорящих. Такие единицы также поддаются некоторой систематизации:

\section{о Вербальные хезитативы:}

11) так / щас щцас щцас я // ага / вот они (ОРД);

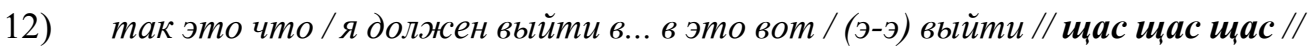
ну подожди / я чем *Н снова / я () да я попьтался написать во всяком случае это (ОРД);

13) что такое? сейчас // *П щас щцас щцас щцас щцас / да да да да да да да // *П шмяк / шмяк / шмяк / шмяк // так / шмяк шмяк // что у нас тут со шмяком получилось / хорошо всё (ОРД).

\section{о Аппроксиматоры разного типа:}

14) то есть я вот / ну я вот так вот сказала / потому что / извините ребята / моя обязанность / это делопроизводство / приказы / то-то то-то то-то mo-mo;

15)_всё это *H что когда вот@тылпнимаешь@когдавот это планирование было / всё знаешь что всё всё это будет зарплата тэ-тэ-тэ / и всё это знаешь вот как бы / человек ждал / ждал / а потом е... а потом раз / оn-оn-оn / и тыл понимаешь / что ничего такое () / оказывается не происходит;

16) во-вторых / компания делает только естественно для тех / в ком они видят наибольшую выгоду // *П даже независимо от того / от качества работы или и так далее;

17) индейская сказка была / я помню / меня впечатлила // что (...) (э-э) раньше (...) мужчины не обладали фаллосом // а он (...) как бы () находился в земле // то есть если женщине что-то нужно / она подходит к нужному там () месту / *П стучит ногой по земле / *B вы... потом вылезает / *C и всё в порядке // а потом там что-то случилось / и его разделили на части // @ (э-э) а как же () мужчины ? *П а вот я не знаю // то есть у них видишь / *П у них в каждой () фишке у них недосмотр // \# *Н ни потребности ни как бь ... я (...) как бы / () я не знаю // у них какое-то ... / ну просто недосмотрели чего-то ребята ! *С боги такие / чёрте чего творят // \# э-та-та-та-та. 
На текстовом же, дискурсивном, уровне нашей устной речи обнаруживаются явления диаметрально противоположного толка, а именно - абсолютно неэкономное расширение, приращение звуковой формы без всякого приращения смысла («сокращаясь» в одних сферах, язык обычно «расширяется» в других - [Будагов 1972: 17]). Анализ материала ЗКРЯ позволил выявить разные способы такого приращения, связанные прежде всего с общей неподготовленностью (спонтанностью) устной речи:

1) чисто фонетические средства:

- неречевые фрагменты звуковой цепи:

18) (э-э) н... (y-y) ну нет! это я в том плане что / (э-э) хорошо / что там его тут же где-то кто-то там чего-то всё-таки повязали / *П ну / наверно рядом находящиеся сообразительные мужчины (ОРД);

19) у уеня такой личный вопрос / в общем (м-м) скажем так ... *Празрешите / я сяду (ОРД).

- паралингвистические элементы (смех, вздох, кашель, цоканье языком, причмокивание, хлюпанье и т. п.):

20) ничего себе! тс(:) / ни хрена себе ! семь мегапикселей ! ну ты даёшь ! *П

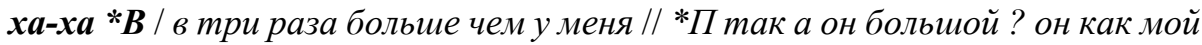
или как мыльница ? (ОРД);

21) э-э этом летом мn l н ещзё-ё ll ьь-н ll н-н ll в следующем l семестре / нам l ещё нужно l сдавать l тест l третьего уровня (CAT);

22) и вот э-э-э если они значит победят / то-о-о смогут захватить / страну целую / (эмоционально) под свою власть / <смех> / или если сами проиграют то должны подчиниться полностью / беспрекословно <вздох > полностью и беспрекословно (САТ).

- растяжки гласных и согласных (y-y нас, н-не надо):

23) положил ручку mы-ы $\int$ э-э не захотел там // печатать что-нибудь / взял ручку написал // <смех> ну-у не знаю мне как это м-м нет и легко как это ко всему относиться и-и очень я при... приспособляюсь к ра... разньлм ситуациям быстро и легко к народу привыкаю (САТ);

24) возможно собрать / $а$-а-а своих друзей / c-c-c какой-нибудь там организовать / дикий пикник / a-а-м не знаю / с танцами / с музыкой (САТ).

- скандированное произнесение слов или частей слов (ска-зал);

- чрезмерная паузация, не связанная с синтагматическим членением речевого потока:

\footnotetext{
${ }^{2}$ Данный контекст - из блока интерферированной русской речи носителей китайского языка, который также входит в состав САТ. О хезитационных явлениях разного типа (в том числе причмокивании, представленном в контексте) в этом материале см., например: [Чэн 2017].
} 
25) *С ну пообщались / да // *П потом на другую какую-то квартиру повёз // *П показывал там всякие скульптуры / но это ну я так понимаю / что это всё () для нас / изысканных людей это () плевать всё это да () а они это () они кичатся этим да вот этим () примитивнымм этим / "П искусством своим // *П $\operatorname{ax}(:)$ (ОРД).

2) лексико-дискурсивные средства (вербализация самого процесса порождения речи):

- вербальные хезитативы разного типа (это самое, как его, я не знаю);

- метакоммуникативы (знаешь, понимаешь, смотри);

- рефлексивы (скажем так, что называется, или как это):

- явления самокоррекции (ср.: «Устная речь необратима - такова ее судьба. Однажды сказанное уже не взять назад, не приращивая к нему нового; “поправить” странным образом значит здесь “прибавить”» [Барт 1989: 541]);

- ритмообразующие единицы (он там сидит там; он вот вышел там);

- дискурсивы (значит, короче, ну вот); и ряд других.

Особый интерес представляет немотивированное на первый взгляд дублирование «синонимичных» (функционально равнозначных) дискурсивных единиц, приводящее к появлению протяженных хезитационных цепочек или комбинаций близких по функции прагматем (обычно ксенопоказателей или аппроксиматоров):

26) $\quad$ а / всё ... а у меня на да... д... дача на этом / как его / на Дунае (ОРД);

27) и он тоже там за мной ухлёстывал и появлялся / и так и сяк и так подкатыввал и пятое и десятое (ОРД);

28) про этого самого (...) (э-э) как его ? (...) (м-м) (э-э) судью Ди (ОРД);

29) колёса раскрутились / и свой в резину выскочил // *B этот / о / вот мол mипа этот / Шумахер(:) / там ну этот / Якоб Мюллер-то (ОРД).

Ср.: «Лаконичность, сжатость выражения может чередоваться с расплывчатостью, дублированием, излишней модификацией одного и того же» [Кожевникова 1985: 512].

Что в результате получается?

30) а вот (э-э) на... н.. вот наше вот это вот (э-э) вот это вот / вот(:) тут / тут сложнеегораздо / @ да // @ потомучто / значит / я вот вот э-э вот эти / ну в принципе / значит / ну / п... по моим / понятиям значит / я жее не отличу так скажем / таджика от узбека что называется / @ да да $\partial a / / @ \partial a ?(\mathrm{OP})$;

31) а ну тут значит тут / это самое // значит / дед // с бабушкой сидят / беседуют / слушают радио // и обсуждают / ох конечные новости что по радио говорят значит на следующей картиночке / э-э это самое / значит старичок / смотрит / на картинку и / э-э хочет тоже так же прокатиться // c / с горы // так значит / собрал / значит взял лыжси / шапку / ну вот / и значит это самое / собрался / поехал // приехал значит / в горы / ну вот 
одел льжси / покатился значит поехал на льжах // с горы / с горы спустился // ну вот / сильно спустился // и / вдруг упал // глаза закрыл // ну вот / думал что разобьётся // ну вот свалился / прямо / в сугроб // ну вот сломал руку // ну теперь пришёл на лечение (САТ);

32) нувот // ну значит / приметы // приметь / это дым / когда он стелется когда он это поднимается и когда это самое / ну вот потом значит примеma / э-э значит э-э роса / если роса затяжная / то к ненастью // и значит примета /м-м это самое горизонт // если горизонт / ну как бы / в общем так это сжимается / то к хорошей погоде // а если / значит / примета / э-э связанная с рыбой / то значит если рыба затихает / то это к ненастью // мак вот (CAT);

33) то есть они знают что (...) знаешь как бы это борьба за местом под солнцеем \# *Н всё-таки ты знаешь // знаешь / у него больше здравого смысла *H если человек работает то он работает / я не знаю // Де... Денис / @ $\boldsymbol{я}$ не знаю...@ Денис здесь такой же наёмный рабочий / каки мы с тобой(ОРД).

Эти две разнонаправленные тенденции - сокращение и приращение - обеспечивают устной речи ту специфику (своеобразный речевой Тяни-Толкай), которая требует постоянного исследовательского внимания.

\section{Литература}

Барт Р. Гул языка // Р. Барт. Избранные работы. Семиотика. Поэтика / Пер. с фр.; сост., общ. ред. и вступ. ст. Г. К. Косикова. М.: Прогресс, 1989. С. 541-544.

Богданова-Бегларян Н. В. (отв. ред.). Звуковой корпус как материал для анализа русской речи: Коллективная монография. Ч. 1. Чтение. Пересказ. Описание / Отв. ред. Н. В. Богданова-Бегларян. СПб.: Филологический ф-т СПбГУ, 2013. 532 с.

Богданова-Бегларян Н.В., Асиновский А.С., Блинова О.В., Маркасова Е.В., Рыко А.И., Шерстинова Т.Ю. Звуковой корпус русского языка: новая методология анализа устной речи // Язык и метод: Русский язык в лингвистических исследованиях XXI века. Вып. 2 / Ред. Д. Шумска, К. Озга. Kraków: Wydawnictwo Uniwersytetu Jagiellońskiego, 2015. С. 357-372.

Богданова-Бегларян Н.В. (отв. ред.). Русский язык повседневного общения: особенности функционирования в разных социальных группах. Коллективная монография / Отв. ред. Н. В. Богданова-Бегларян. СПб.: Лайка, 2016. 244 с.

Богданова-Бегларян Н.В., Шерстинова Т. Ю., Зайдес К.Д. Корпус «Сбалансированная Аннотированная Текстотека»: методика многоуровневого анализа русской монологической речи // Анализ разговорной русской речи (AP $\left.\mathrm{AP}^{3}-2017\right)$ : Труды Седьмого междисциплинарного семинара / Науч. ред. Д. А. Кочаров, П.А. Скрелин. СПб.: Политехника-принт, 2017а. С. 8-13.

Богданова-Бегларян Н. В., Шерстинова Т. Ю., Блинова О. В., Мартыненко Г. Я. Корпус «Один речевой день» в исследованиях социолингвистической вариативности русской разговорной речи // Анализ разговорной русской речи ( $\left.\mathrm{AP}^{3}-2017\right)$ : 
Труды седьмого междисциплинарного семинара / Науч. ред. Д.А. Кочаров, П. А. Скрелин. СПб.: Политехника-принт, 2017б. С. 14-20.

Бодуэн де Куртенэ И. А. Об общих причинах языковых изменений // И. А. Бодуэн де Куртенэ. Избранные труды по общему языкознанию. Т. І. М.: Изд-во АН CCCP, 1963. C. 222-254.

Будагов Р. А. Определяет ли принцип экономии развитие и функционирование языка? // Вопросы языкознания. 1972. № 1. С. 17-36.

Кожевникова $К$. О смысловом строении спонтанной устной речи // Новое в зарубежной лингвистике. Вып. XV. Современная зарубежная русистика. М.: Прогресс, 1985. С. 512-524.

Национальный корпус русского языка [Электронный ресурс]: база данных. Электрон. дан. - Режим доступа: http://ruscorpora.ru (свободный). - Загл. с экрана.

Пауль Г. Принципы истории языка. М.: Изд-во иностранной лит-ры, 1960. 501 с.

Спенсер Г. Основные начала. Киев: Вища школа, 1986. 375 с.

Стойка Д. А. Редуцированные формы русской речи: лингвистический и экстралингвистический аспекты. Дис. ... канд. филол. наук. СПб., 2017. [Машинопись].

Чэн Ч. Русская спонтанная речь на неродном языке: анализ хезитаций (на материале русской речи китайцев) // Вестник Пермского университета. Российская и зарубежная филология. 2016. № 1 (33). С. 53-62.

Bogdanova-BeglarianN., Sherstinova T., Blinova O., BaevaE., Martynenko G., RykoA. Sociolinguistic Extension of the ORD Corpus of Russian Everyday Speech // Speech and Computer. $18^{\text {th }}$ International Conference, SPECOM 2016. Budapest, Hungary, August, 23-27, 2016. Proceedings / A. Ronzhin, R. Potapova, G. Németh (eds). P. 659-666.

Frei H. La Grammaire des Fautes. Paris, 1929. 317 p.

Passy P. Etude sur les Changements Phonetiques et Leurs Caracteres Generaux. Paris: Librairie Firmin-Didot, 1890. 270 p.

\author{
Natalia V. Bogdanova-Beglarian \\ Saint-Petersburg State University \\ (Russia, Saint-Petersburg) \\ n.bogdanova@spbu.ru
}

\title{
PHONETIC T'ANI-TOLKAJ: TWO DIVERGENT TRENDS IN THE ORAL TEXT COTSTRUCTION
}

The article is dedicated to the descriptions of two trends in the oral text construction. At the lexical and syntactic levels, the law of economy is particularly active and fruitful in Russian, leading to some compression or reduction of speech units, and so creating the other ones, new, being at different stages of their path to recognition as a system of language (destruction - in a way - leads to creation). The most striking example of 
such creation as a result of compression are the lexicalized reduced forms of many, especially super-frequent, Russian words: tbishcha, shchas, pijs'at, zdras'te, s'odn'a, chek (chelovek), grit and so on. The law of economy also leads to the use in speech of approximants of various types that replace a number of enumerations, both transferred by the speaker or his own ones: $i$ v'o takoe (prochee), p'atoe-des'atoe, to-s'o, bla-bla-bla. On the other hand, on the textual, discursive level of our oral speech, phenomena of diametrically opposite persuasion are revealed, namely, absolutely uneconomical expansion, increment of form without any increment of meaning. This increment is realized due to a large number of unmotivated (hesitation) pauses, non-verbal hesitatives (e-e, $a-a, m-m)$, and also by using various pragmatic units that help the speaker to generate and structure his speech: these are verbal hesitatives (eto samoe, kakjego, ja ne znaju, nu v obshchem), paralinguistic phenomena (laughter, sigh, cough, smacking, tongue clipping, etc.) and so on. These two different trends - reduction and increment - provide oral speech with the specificity (a kind of verbal T'ani-Tolkaj) which requires constant research attention.

Key words: spontaneous speech, the law of economy, the reduced form of the word, speech compression, hesitation, verbal hesitative, pragmatic items

\section{References}

Bart R. [The Hum of Language]. R. Bart. Izbrannye raboty. Semiotika. Poetika. Moscow, 1989. P. 541-544 (In Russ.).

Bogdanova-Beglarian N.V. (ed.). Zvukovoj korpus kak material dlya analiza russkoj rechi. Kollektivnaya monografiya. Chast' 1. CHtenie. Pereskaz. Opisanie. [Speech Corpus as a Base for Analysis of Russian Speech. Collective Monograph. Part 1. Reading. Retelling. Description] / Bogdanova-Beglarian, N. V. (ed.). St. Petersburg, 2013. 532 p.

Bogdanova-Beglarian N.V., Asinovsky A.S., Blinova O.V., Markasova E.V., Ryko A. I., Sherstinova T. Ju. [Speech Corpus of Russian Language: a New Methodology for Analyzing of Oral Speech]. Jazyk i metod: russkij jazykv lingvisticheskikh issledovaniakh XXI veka. Vyp. 2 / D. Shumska, K. Ozga (eds). Crakow, 2015. P. 357-372 (In Russ.).

Bogdanova-Beglarian N.V. (ed.). Russkij yazyk povsednevnogo obshcheniya: osobennosti funkcionirovaniya $v$ raznyh social'nyh gruppah. Kollektivnaya monografiya. [Everyday Russian Language in Different Social Groups. Collective Monograph]. Bogdanova-Beglarian, N.V. (ed.). St. Petersburg, Laika Publ., 2016. 244 p.

Bogdanova-Beglarian N., Sherstinova T., Blinova O., Baeva E., Martynenko G., Ryko A. Sociolinguistic Extension of the ORD Corpus of Russian Everyday Speech. Speech and Computer. 18 $8^{\text {th }}$ International Conference, SPECOM 2016. Budapest, Hungary, August, 23-27, 2016. Proceedings / A. Ronzhin, R. Potapova, G. Németh (eds). P. 659-666.

Bogdanova-Beglarian N. V., Sherstinova T. Ju., Zajdes K. D. [Corpus "Balanced Annotated Text Library": Method of Multilevel Analysis of Russian Monological Speech]. Analiz razgovornoj rechi (AR ${ }^{3}$ 2017): trudy sed'mogo mezhdisciplinarnogo seminara. D. A. Kocharov, P. A. Skrelin (eds). St. Petersburg, 2017a. P. 8-13 (In Russ.). 
Bogdanova-Beglarian N.V., Sherstinova T. Ju., Blinova O.V., Martynenko G. Ja. [Corpus “One Speaker's Day" in Studies of Sociolinguistic Variability of Russian Colloquial]. Analiz razgovornoj rechi (AR ${ }^{3}$-2017): trudy sed'mogo mezhdisciplinarnogo seminara / D. A. Kocharov, P. A. Skrelin (eds). St. Petersburg, 2017b. P. 14-20 (In Russ.)

Boduen de Kurtene I. A. [On Common Causes of Language Change]. I. A. Boduen de Kurtene. Izbrannye trudy po obshchemu jazykoznaniju. T. I. [I. A. Boduen de Kurtene. Selected works on general linguistics. Vol. I.]. Moscow, 1963. P. 222-254 (In Russ.).

Budagov R.A. [Determines whether the Principle of Economy Development and Functioning of Language?]. Voprosy jazykoznania. 1972. No. 1. P. 17-36 (In Russ.).

Chen Ch. [Spontaneous Speech in Russian as Foreign Language: Analysis of Hesitation (a Case Study of Chinese Students' Speech)]. Vestnik Permskogo universiteta. Rossijskaja i zarubezhnaja filologia. 2016. No. 1 (33). P. 53-62 (In Russ.).

Frei H. La Grammaire des Fautes. Paris, 1929. 317 p.

Kozhevnikova K. [On Semantic Structure of Spontaneous Speech]. Novoe v zarubezhnoj lingvistike. Vyp. XV. Sovremennaja zarubezhnaja rusistika. Moscow, Progress Publ., 1985. P. 512-524 (In Russ.).

Russian National Corpus. Available at: http://ruscorpora.ru

Passy P. Etude sur les Changements Phonetiques et Leurs Caracteres Generaux. Paris, Librairie Firmin-Didot, 1890. 270 p.

Paul' G. Principy istorii yazyka. [Principles of Language History]. Moscow, IL Publ., 1960. $501 \mathrm{p}$.

Spenser G. Osnovnye nachala [Basic Principles]. Kiev, Vysshaya shkola Publ., 1986. $375 \mathrm{p}$.

Stojka D. A. Reducirovannye formy russkoj rechi: lingvisticheskij i ehkstralingvisticheskij aspekty. Dis. ... kand. filol. nauk. [Reduced Forms in Russian Speech: Linguistic and Extralinguistic Aspects]. PhD Thesis. St. Petersburg, 2017. 211 p. (typescript). 